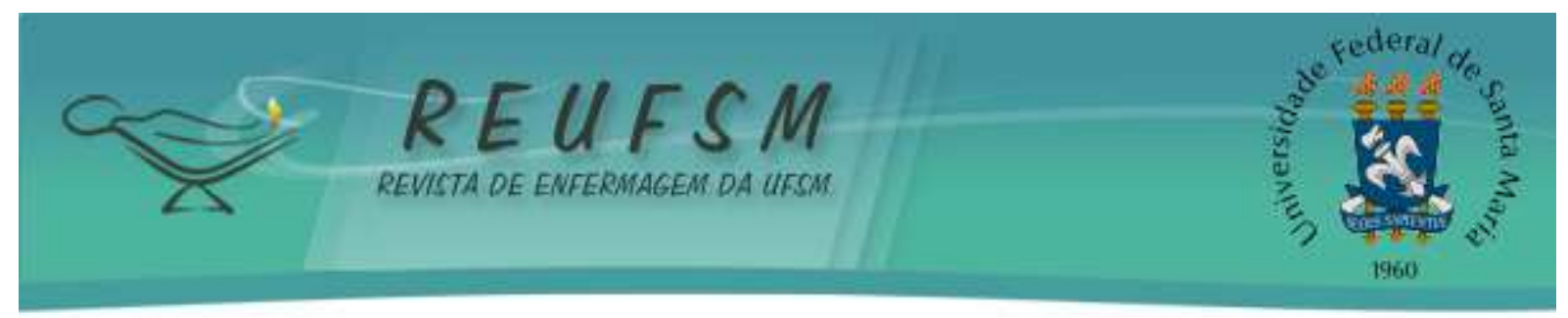

\title{
PROCESSO DE ENFRENTAMENTO EMOCIONAL DA EQUIPE DE ENFERMAGEM NO CUIDADO DE CRIANÇAS COM CÂNCER HOSPITALIZADAS
}

\author{
EMOTIONAL CONFRONTATION PROCESS OF THE NURSING TEAM IN THE \\ CARE OF HOSPITALIZED CHILDREN WITH CANCER
}

\section{PROCESO DE ENFRENTAMIENTO EMOCIONAL DEL EQUIPO DE ENFERMERÍA EN EL CUIDADO DE NIÑOS CON CÁNCER HOSPITALIZADOS}

Doi: $10.5902 / 2179769227319$

\author{
Marcella Rocha Teixeira ${ }^{1}$ \\ Nádia Fontoura Sanhudo ${ }^{2}$ \\ Denise Cristina Alves de Moura ${ }^{3}$ \\ Maria Tereza Ramos Bahia ${ }^{4}$
}

RESUMO: Objetivo: conhecer o processo de enfrentamento emocional da equipe de enfermagem no cuidado de crianças com câncer em uma unidade de internação hospitalar. Método: estudo descritivo, abordagem qualitativa e desenvolvido no setor de oncologia pediátrica. Foram entrevistados 10 profissionais de enfermagem, e para a análise dos dados, utilizou-se a análise temática. Resultados: emergiram duas categorias: estratégias facilitadoras para o enfrentamento emocional do processo de cuidar da criança com câncer; comportamentos e desafios apontados pela equipe de enfermagem no enfrentamento emocional do processo de cuidar da criança com câncer. Considerações finais: no enfrentamento emocional da equipe de enfermagem no cuidado a crianças com câncer existe uma dualidade entre demonstração e repressão dos sentimentos. Destaca-se a importância do apoio psicológico à equipe de enfermagem, a oferta de momentos de orientação e a troca de experiências.

Descritores: Enfermagem; Enfermagem pediátrica; Enfermagem oncológica; Adaptação psicológica; Cuidados de enfermagem

ABSTRACT: Aim: to know the emotional coping process of the nursing team in the care of children with cancer in a hospital admission unit. Method: descriptive study, with a qualitative approach and developed in the pediatric oncology sector. We interviewed 10 nursing professionals, and for the data analysis, the thematic analysis was used. Results: two categories emerged: strategies to facilitate the emotional coping of the process of caring for the child with cancer; behaviors and challenges pointed out by the nursing team in the emotional coping of the process of caring for the child with cancer. Final considerations: in the emotional coping of the nursing team in the care of children with cancer, there is a duality between demonstration and repression of feelings. The importance of psychological support to the nursing team, provision of orientation moments and exchange of experiences is highlighted.

\footnotetext{
${ }^{1}$ Enfermeira. Graduada pela Faculdade de Enfermagem da Universidade Federal de Juiz de Fora. Juiz de Fora. Minas Gerais. Brasil. E-mail: marcellateixeira_94@hotmail.com

${ }^{2}$ Enfermeira. Doutora em Enfermagem. Professora da Faculdade de Enfermagem da Universidade Federal de Juiz de Fora. Juiz de Fora. Minas Gerais. Brasil. E-mail: nadiasanhudo@ gmail.com

3 Enfermeira. Mestre em Enfermagem. Doutoranda em Saúde Coletiva da Faculdade de Medicina da Universidade Federal de Juiz de Fora. Juiz de Fora. Minas Gerais. Brasil. E-mail: denisematipo@yahoo.com.br

${ }^{4}$ Enfermeira Mestre em Enfermagem. Professora da Faculdade de Enfermagem da Universidade Federal de Juiz de Fora. Juiz de Fora. Minas Gerais. Brasil. E-mail: mtbahia@uol.com.br
} 


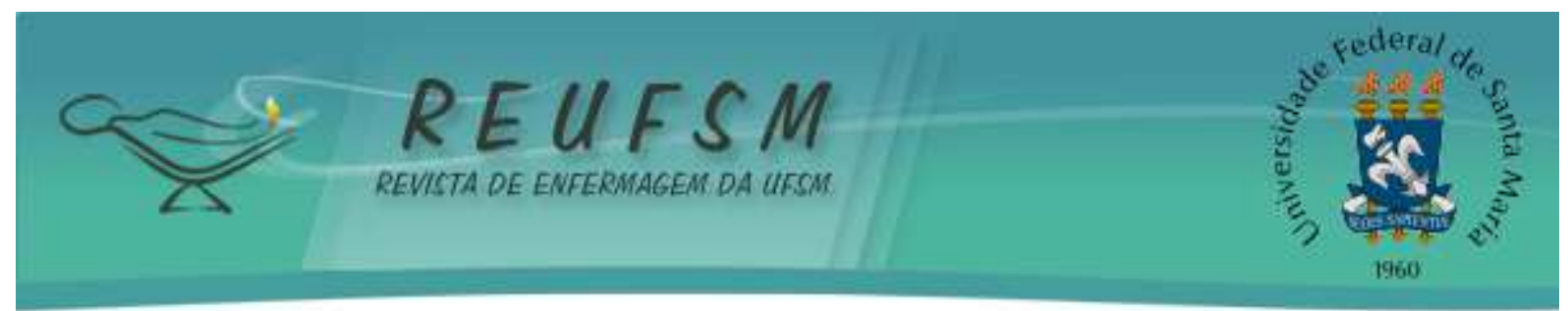

Descriptors: Nursing; Pediatric nursing; Oncology nursing; Adaptation psychological; Nursing care

RESUMEN: Objetivo: conocer el proceso de enfrentamiento emocional del equipo de enfermería en el cuidado de niños con cáncer en una unidad de internación hospitalaria. Método: estudio descriptivo, de perspectiva cualitativa, desarrollado en un sector de oncología pediátrica. Fueron entrevistados 10 profesionales de enfermería, y para el análisis de los datos se utilizó el análisis temático. Resultados: se evidenció dos categorías: estrategias que faciliten el enfrentamiento emocional del proceso de cuidar del niño con cáncer; comportamientos y desafíos revelados por el equipo de enfermería en el enfrentamiento emocional del proceso de cuidar del niño con cáncer. Consideraciones finales: en el enfrentamiento emocional del equipo de enfermería en el cuidado de niños con cáncer existe una dualidad entre demostración y represión de los sentimientos. Se destaca la importancia del apoyo psicológico al equipo de enfermería, la oferta de momentos de orientación y el intercambio de experiencias.

Descriptores: Enfermería; Enfermería pediátrica; Enfermería oncológica; Adaptación psicológica; Atención de enfermería

\section{INTRODUÇÃO}

O câncer é considerado um dos maiores problemas de saúde pública em todo o mundo. ${ }^{1}$ No Brasil, o câncer infantil é a primeira causa de morte por doença, perfazendo $7 \%$ do total entre crianças e adolescentes na faixa etária entre 1 a 19 anos, sendo as leucemias os tumores mais frequentes, assim como os do sistema nervoso central e os linfomas. ${ }^{2}$

Entende-se que para cuidar de crianças com câncer, existem algumas particularidades como na pediatria, em que qualquer procedimento ou situação deve ser avaliado e executado com mais delicadeza e cautela devido à maior vulnerabilidade da criança, o que exige dos profissionais de enfermagem grande sensibilidade e equilíbrio emocional, uma vez que estes desempenham papel central como cuidadores de apoio emocional. ${ }^{3-4}$ Profissionais que trabalham com oncologia pediátrica podem estar expostos a altas cargas de estresse, sendo necessário apoio psicológico para evitar o desgaste. ${ }^{5}$

Assim, para se prestar uma assistência de qualidade, é preciso que haja uma reflexão sobre o enfrentamento emocional dos profissionais inseridos no processo de cuidar da criança com câncer. Quando a oncologia se associa com a pediatria essas cargas se somam, adquirindo um peso muito maior devido às repercussões do processo saúde-doença, sendo impossível não considerar que a equipe de enfermagem sofra influências emocionais no cuidado da criança hospitalizada com câncer. ${ }^{6-7}$ 


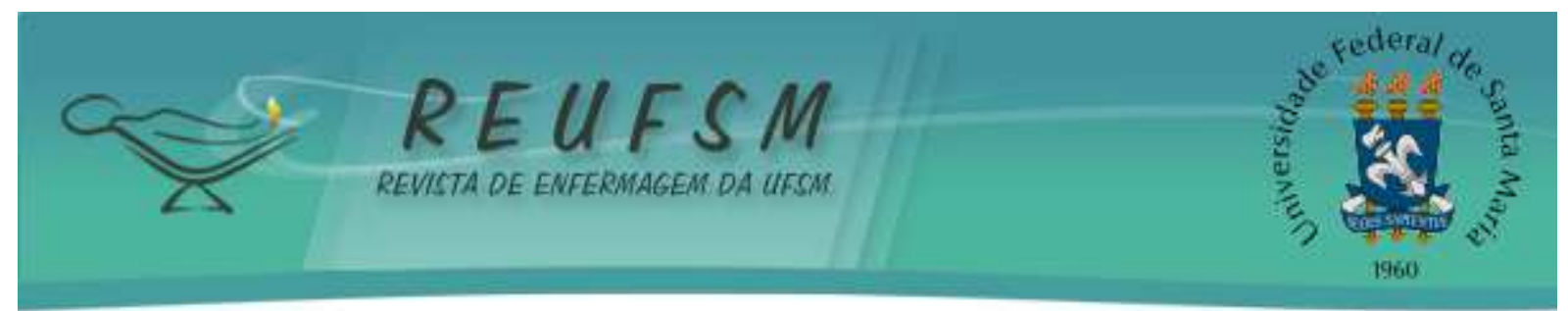

Neste estudo, o enfrentamento emocional é colocado como a forma com a qual o profissional lida com as situações vivenciadas que surgem no processo de trabalho. Dessa maneira, não se trata de confrontar-se com suas emoções, mas sim de desenvolver estratégias de enfrentamento que auxiliem a conviver com determinadas circunstâncias. ${ }^{8}$

Para o cuidado da criança com câncer, o enfermeiro deve desenvolver competências e habilidades gerenciais para atender as complexas necessidades da criança e de sua família e também considerar as necessidades e singularidades da equipe de enfermagem. ${ }^{9-10}$ Contudo, são incipientes as pesquisas que apontam estratégias para atuar junto à equipe de enfermagem, que tanto necessita de capacitação e apoio psicológico. ${ }^{10}$

Diante da problemática apresentada questiona-se: como a equipe de enfermagem lida com as demandas e desafios emocionais decorrentes do cuidado à criança com diagnóstico de câncer? Assim, objetivou-se conhecer o processo de enfrentamento emocional da equipe de enfermagem no cuidado de crianças com câncer em uma unidade de internação hospitalar.

\section{MÉTODO}

Trata-se de uma pesquisa descritiva, com abordagem qualitativa. O cenário foi uma instituição hospitalar habilitada como Unidade de Assistência de Alta Complexidade em Oncologia (UNACON), situada no município de Juiz de Fora, na região da zona mata mineira, Brasil.

Nesse contexto, a investigação foi realizada na unidade de internação de pediatria do referido cenário e com os profissionais de enfermagem. Como critérios de inclusão definiramse: ser profissional de enfermagem, estar lotado no setor de pediatria da instituição e estar trabalhando no setor em questão por, no mínimo, três meses. Os critérios de exclusão foram: profissionais que estavam de férias ou licença de trabalho no período de coleta de dados.

Foram convidados a participar deste estudo todos os 12 profissionais do setor. Dentre eles, um profissional não aceitou participar e outro não obedecia aos critérios de tempo de trabalho no setor. Desse modo, foram analisadas 10 entrevistas para produzir este estudo. Além disso, foi realizado o teste piloto com um profissional da instituição que, no momento da coleta de dados, não estava lotado no setor pediátrico, mas que possuía atuação prévia na área.

Os dados foram coletados nos meses de maio a junho de 2016, por meio de entrevistas semiestruturadas que foram gravadas em áudio e, posteriormente, transcritas. Preservando a identidade dos entrevistados, optou-se por substituir o nome dos indivíduos, de forma 


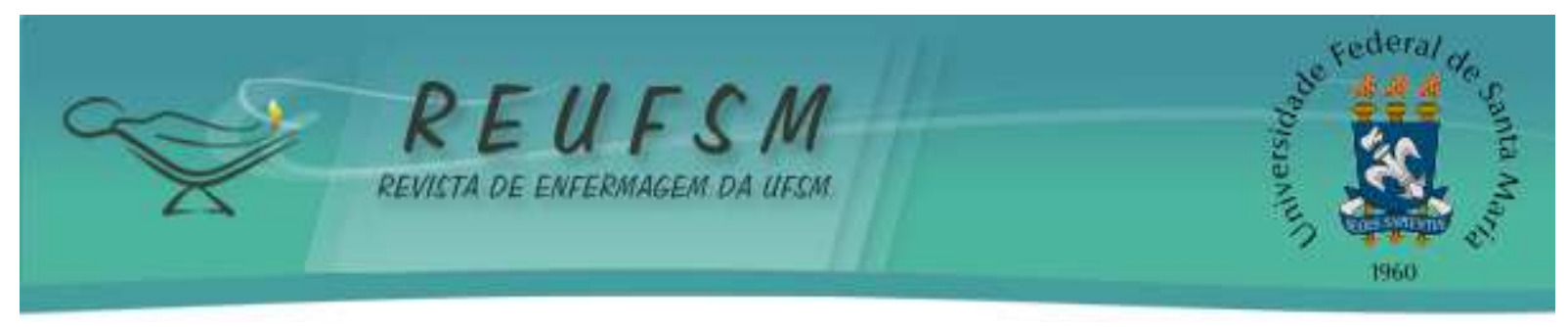

aleatória, pela letra E, seguido, de um número arábico. Para a caracterização dos participantes do estudo foram empregadas as seguintes variáveis: categoria profissional, idade, tempo de formação, tempo de trabalho em pediatria, tempo de trabalho no setor pediátrico da instituição cenário da pesquisa, se possuíam alguma especialização e em qual área.

As entrevistas duraram em média 30 minutos e ocorreram no horário de trabalho. Para norteá-las, foram utilizadas as seguintes perguntas: Fale-me quais são suas emoções no cuidado da criança com câncer e como você lida com elas? O que você costuma fazer (meios e recursos) no seu dia a dia para lidar com suas emoções? Como essas estratégias (ações) auxiliam você para cuidar de crianças com câncer? Como você costuma auxiliar seus colegas quando percebe que estão com algum tipo de tensão emocional relacionada ao processo de cuidar das crianças? Na sua visão, o que poderia ser desenvolvido junto à equipe de enfermagem para ajudar os profissionais a lidar com suas emoções durante o processo de cuidar da criança com câncer? Existe algo que não foi perguntado que você ache importante e gostaria de falar a respeito?

Por tratar-se de uma pesquisa com seres humanos, ela foi desenvolvida atendendo aos critérios da Resolução $n^{\circ}$ 466/2012 do Conselho Nacional de Saúde. ${ }^{11}$ O projeto foi aprovado pelo Comitê de Ética e Pesquisa da Universidade Federal de Juiz de Fora sob o parecer no 1.459.587, em 21 de março de 2016.

Para a análise dos dados, utilizou-se a Análise Temática, que consiste em descobrir os núcleos de sentido que compõem uma comunicação, partindo do pressuposto de que a presença e frequência desses núcleos possuam algum significado para o objeto analítico do estudo. ${ }^{12}$

\section{RESULTADOS E DISCUSSÃO}

Foram entrevistados cinco enfermeiros e cinco técnicos de enfermagem. Desses dez participantes, seis eram do sexo feminino e quatro do sexo masculino, com faixa etária entre 27 e 43 anos. O tempo de atuação profissional no setor de pediatria oncológica era de seis meses a 15 anos.

Todos os enfermeiros entrevistados relataram ter uma ou mais pós-graduação lato sensu; destes apenas um apontou ter especialização em oncologia, o que revela uma condição não só do cenário desta pesquisa, mas também de outros lugares. A área de oncologia ainda é pouco abordada durante a graduação em enfermagem, sendo que os profissionais constroem seu conhecimento por meio das vivências adquiridas com o tempo ou por busca individual de conhecimentos a respeito. ${ }^{13}$ 


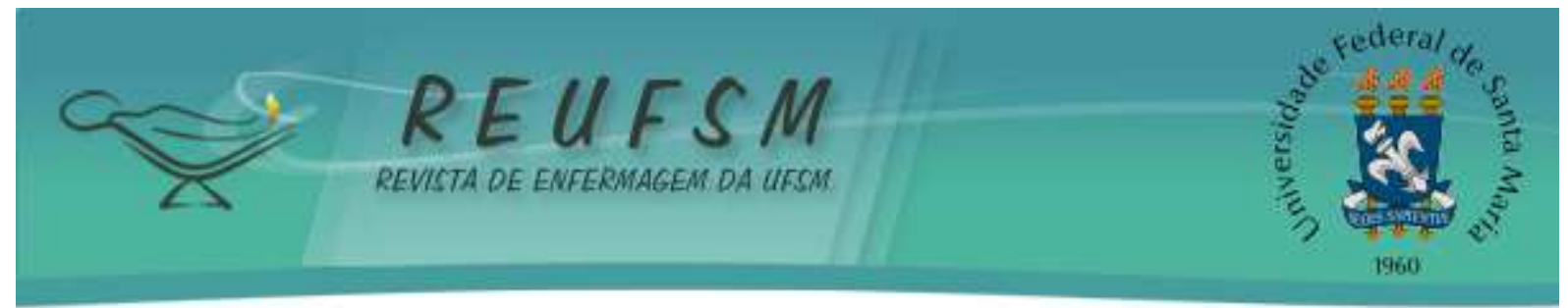

Os resultados obtidos foram divididos em duas categorias apresentadas no quadro 1.

\begin{tabular}{|l|l|}
\hline \multicolumn{2}{|c|}{ Categorias emergentes do processo de enfrentamento emocional da equipe de enfermagem no cuidado } \\
de crianças com câncer
\end{tabular}

Quadro 1 - Categorias emergentes do processo de enfrentamento emocional da equipe de enfermagem no cuidado de crianças com câncer. Juiz de Fora, MG, Brasil, 2016.

\section{Estratégias facilitadoras para o enfrentamento emocional do processo de cuidar da criança com câncer}

Constatou-se que brincar e divertir as crianças internadas são meios utilizados pelos profissionais de enfermagem do setor de pediatria oncológica para se relacionar melhor e conseguir realizar seu trabalho de maneira menos estressante para ambas as partes. Os profissionais se preocupam com as limitações físicas da criança, respeitando o tratamento.

[...] dar atenção naquele momento, não passar apenas para uma visita. Fazer diferente. [...] a criança com câncer fica muito debilitada [...] é uma festinha, aniversário [...], vamos empurrar o velotrol [brinquedo infantil de material plástico contendo três rodas e dois pedais, que pode ser usado para entretenimento.] com ele e a bomba junto, mostrar que ele não é incapaz [...]. (E5)

É possível inferir que o ato de brincar com as crianças é uma estratégia que pode estar presente embora, muitas vezes, esteja debilitada, uma vez que o lúdico não pode ser esquecido pelos profissionais. O uso do brincar pela equipe de enfermagem serve como redutor da tensão proveniente dos procedimentos desconfortáveis aos quais a criança é submetida e também aponta algumas restrições existentes, visto que as crianças hospitalizadas com câncer podem ter limitações físicas ou não desejarem brincar nesse momento difícil, sendo necessária uma avaliação de suas condições para brincar. ${ }^{14}$ 


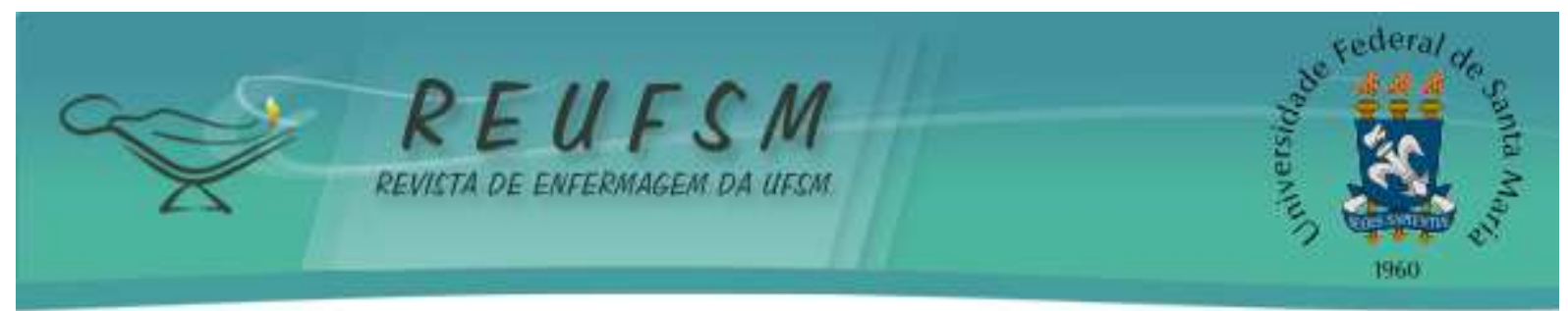

A conversa com o colega foi apontada pelos participantes como um recurso facilitador, sendo entendida como uma forma de extravasar as emoções para amenizar as repercussões negativas das emoções vivenciadas.

[...] ela é do outro plantão, a gente conversa muito em relação ao hospital e às crianças [...]. (E6)

Destaca-se a importância do diálogo entre a equipe para fortalecer as relações interpessoais e o vínculo, além de ser importante para a qualidade da assistência de enfermagem. O uso da comunicação é essencial para a gestão emocional dos profissionais, para a redução do estresse e a promoção do bem-estar entre a equipe, cuja finalidade é o compartilhamento de experiências e práticas de cada membro da equipe, esclarecimento de ideias, visões e perspectivas. ${ }^{15}$

Nessa perspectiva, em relação ao enfermeiro, foi levantado nas entrevistas que ele tem papel importante no diálogo entre a equipe e que deveria dedicar-se mais a esta ação.

[...] o enfermeiro deve trabalhar, conversar, dialogar [...] nossa equipe é boa, pois conversa [...]. (E4)

O enfermeiro deve estar atento ao seu protagonismo no processo de liderança na equipe de enfermagem, desenvolvendo suas competências e habilidades gerenciais para atender às necessidades de sua equipe. A cooperação do líder com os demais membros contribui para continuidade do cuidado, a melhoria dos relacionamentos interpessoais e a diminuição do desgaste emocional. ${ }^{16}$

O apoio na religião relatado por alguns entrevistados ajuda a suportar as demandas emocionais das situações do cuidado em oncologia pediátrica, dando conforto psicológico, principalmente quanto à morte. Nas entrevistas, alguns relataram pedir a Deus forças para lidar com o cotidiano do cuidar, chegando a conformar-se com a morte e encarando-a como o fim do sofrimento que a criança vem vivenciando, como em "peço muito a Deus muita força para lidar com tudo”. (E7)

Dessa forma, a religião ajuda a lidar melhor com impactos emocionais do cuidar em meio ao processo de morte, contudo, professar uma crença religiosa não torna o profissional melhor cuidador nem significa que este esteja mais preparado para lidar com a morte do paciente. ${ }^{17}$

A necessidade de espairecer e viver uma vida longe da rotina de trabalho e das situações negativas a que são expostos foi colocada como um mecanismo de desligar-se desse 


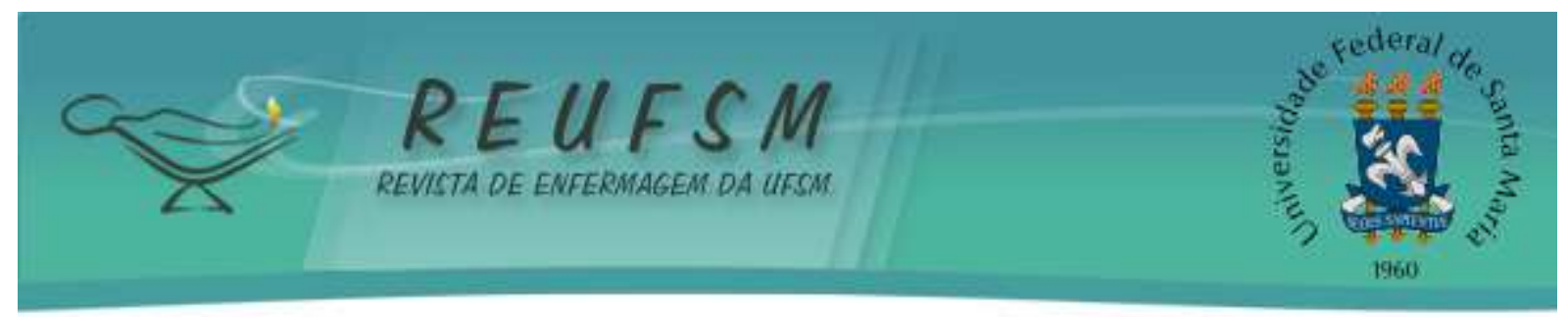

contexto quando não estão trabalhando, de forma a garantir que consigam aguentar o desgaste emocional proveniente do processo de cuidar.

[...] Eu procuro desligar de tudo do trabalho [...] se morre uma criança não tem como você não levar isso para casa, eu vou sair e vou esquecer tudo, mas o que mais procuro fazer é isso porque a gente lida com muita coisa [...] se a gente ficar pensando nisso em casa, o tempo inteiro, a gente não consegue viver. (E8)

Essa atitude assumida pelos profissionais sendo considerada como um mecanismo de defesa, a qual de alguma forma reprime suas emoções é uma estratégia que, muitas vezes pode promover um distanciamento do profissional em relação a essa situação.

A repressão como estratégia adotada pela enfermagem neste contexto, pode ser consequência da inexistência de um espaço de discussão que permita ao profissional a expressão de seus sentimentos, o que pode desencadear defesas como o distanciamento, a falta de sensibilidade ou um equilíbrio superficial, suficiente apenas para manter o status quo. ${ }^{18}$ Essa interpretação indica que a repressão tende a ser recorrente na enfermagem oncológica pediátrica, utilizada como um mecanismo de defesa pelos profissionais que buscam desligar-se das questões vividas no processo de cuidar.

Percebe-se que os profissionais mesmo estando em um ambiente onde são frequentes as situações de sofrimento, sentem satisfação em trabalhar e estar no convívio das crianças em tratamento do câncer e também nos momentos de desfecho positivo do tratamento.

[...] na verdade isso é um sentimento que a gente carrega, a gente se vê importante [...]. (E9)

É possível inferir que o relacionamento e o vínculo estabelecidos entre os profissionais, as crianças e os familiares, podem ser uma fonte de satisfação e prazer, o que contribui para dar um sentido ao trabalho. Os profissionais, mesmo sofrendo durante o cuidado, conseguem obter o sentimento de gratificação pela função exercida, ${ }^{19}$ o que demonstra que experimentam sentimentos e emoções que se contradizem.

Diante de alterações emocionais e psicológicas, os entrevistados relataram que consideram necessários o apoio psicológico e a capacitação para trabalhar no cenário de oncologia pediátrica. Dessa forma, sugerem momentos de reuniões para capacitação sobre como lidar com suas emoções e como se comportar com mais segurança emocional em situações de sofrimento dos pacientes e familiares. 


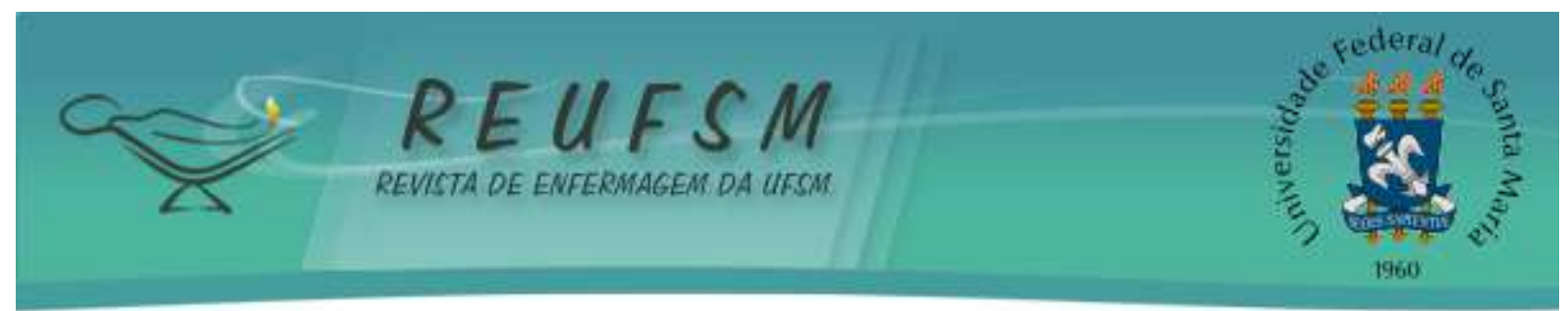

[...] mais capacitação aqui dentro como cursos, dinâmicas [...] ver as dicas da psicóloga [...]. (E5)

De acordo com alguns autores, é necessário buscar estratégias para promover o aprimoramento do conhecimento técnico e teórico em oncologia pediátrica para facilitar o processo de tomada de decisão, comunicação e educação colaborativa como em reuniões de equipe. ${ }^{20}$ Em outro estudo, a criação de momentos para equipe de discussão de casos, cursos, debates, ou ensinos clínicos foi indicada como uma oportunidade para compartilhar experiências, de modo a ajudar o enfermeiro e demais profissionais na compreensão dos processos complexos do adoecimento, do viver e do morrer humano. ${ }^{21}$

Quanto ao apoio psicológico, os profissionais ressaltaram que este deveria existir não só para os que trabalham no setor de pediatria, mas para todos os profissionais da área de oncologia.

Eu acho que todo profissional, não só da pediatria, do hospital de oncologia em geral, deveria ter esse acompanhamento [...]. (E2)

$\mathrm{O}$ apoio psicológico contínuo oferecido à equipe de enfermagem em oncologia é uma estratégia para o enfrentamento emocional, auxiliando no alívio do sofrimento desses profissionais em sua rotina de cuidar em oncologia pediátrica. ${ }^{10}$

\section{Comportamentos e desafios apontados pela equipe de enfermagem no enfrentamento emocional do processo de cuidar da criança com câncer}

Os dados apontam que os profissionais de enfermagem tendem a demonstrar resistência em trabalhar no setor de pediatria oncológica. Desse modo, os entrevistados consideraram este setor um cenário difícil de realizar suas atividades assistenciais, pois justificam que como os pacientes são crianças, a carga emocional é intensificada durante a produção do cuidado.

[...] mesmo a gente trabalhando há muito tempo, tem situações que são bem delicadas e bem complicadas. (E1)

[...] aqui no hospital tem muita gente que não gosta de trabalhar com criança [...] eu não queria vir, mas agora que estou aqui, não tenho nenhum problema. (E2)

Segundo estes relatos, após a inserção na rotina do setor de pediatria, essa dificuldade preconcebida se modifica e os profissionais passam a se sentir, na medida do possível, confortáveis em meio à situação, o que não significa que parem de sofrer ou se abalar, independentemente do seu tempo de experiência nesse tipo de cuidado. Estudos apontam a existência de desafios e dificuldades no processo de cuidar da criança com câncer e, neste 


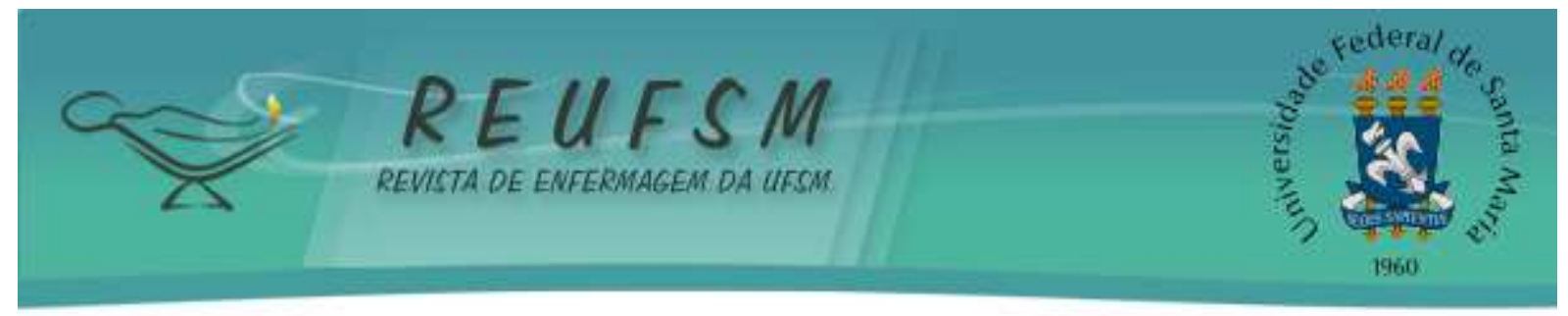

sentido, revela-se a necessidade de um apoio psicológico e constante capacitação para se adaptarem, sentindo-se acolhidos e motivados para permanecerem no setor de pediatria. ${ }^{10}$

Outro comportamento do profissional de enfermagem diante da criança em tratamento do câncer presente nos discursos dos participantes, foi o mecanismo de tentar evitar transparecer suas emoções na presença da criança e familiares.

[...] nós enfermeiros não podemos deixar que o emocional fale mais alto. Muitas das vezes, a gente tem que engolir a seco, sorrir, mostrar que tem uma firmeza nas decisões, para que você não passe sofrimento, para que você não passe mais dor do que já tem. (E3)

[...] a gente tem que segurar o choro perto das crianças, a gente tem que mostrar que está forte para lhes passar força, mas depois eu choro porque é muito triste. (E4)

Em relação a esse tipo de atitude, especialmente em oncologia pediátrica, percebe-se que isso se apresenta como uma proteção ao próprio sofrimento psíquico durante a realização de um procedimento ou contato com a criança e sua família, em que o profissional não deixa que os sentimentos aflorem durante o cuidado, passando uma postura de aparente neutralidade. O sofrimento vivenciado pela equipe, muitas vezes suprimido, leva à necessidade de buscar estratégias para trabalhar seus sentimentos, como tentativa de evitar o processo de exaustão devido à ansiedade, preocupações, medo e angústia vivenciados no processo de cuidar do paciente pediátrico em oncologia. ${ }^{22}$

Os resultados apontaram haver uma tendência entre os entrevistados que já possuem filhos em enfrentar maior dificuldade para lidar emocionalmente com a situação e rotina do cuidado de crianças com câncer: “[...] para gente que tem filhos é complicado” (E2).

Pode-se inferir que o profissional de enfermagem passa a enxergar a criança sob a ótica que o faria se fossem seus filhos, intensificando o envolvimento com esses pacientes.

As profissionais de enfermagem, quando são mães, vivenciam um momento singular ao cuidar das crianças com doença oncológica avançada, envolvendo-se de forma diferenciada com a criança, uma vez que se colocam no lugar das mães dessas crianças. Nesse aspecto, cuidar torna-se mais complexo e triste. ${ }^{23}$

Os participantes declararam ser um desafio lidar com as emoções na rotina de cuidar, pois se sentem abalados. O sofrimento é intensificado por se tratar de uma criança, já que pela forma de pensar da sociedade, ela estaria no começo da vida. Além disso, o envolvimento é mencionado como resultado durante a rotina de cuidar, expondo-lhes certa fragilidade pessoal. 


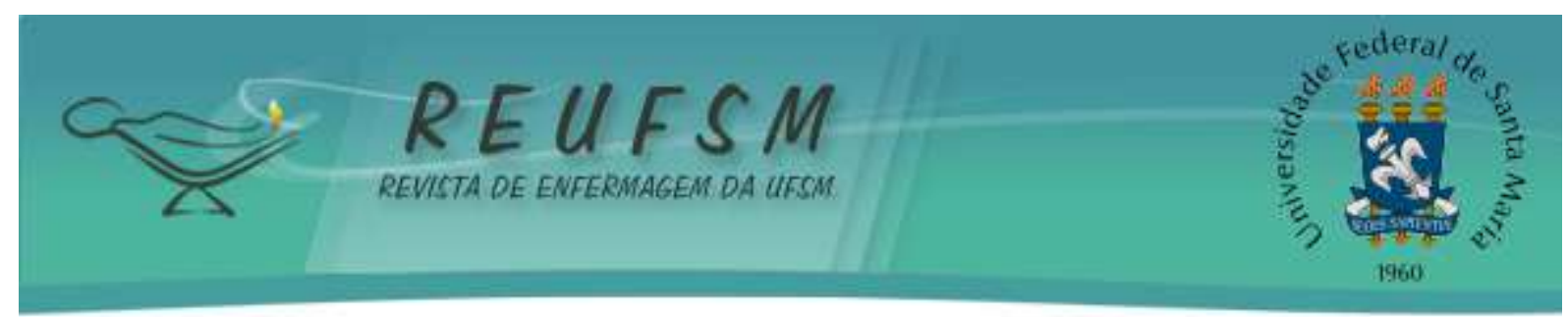

Porque é um serzinho que mal veio à vida e já está sofrendo com uma doença [...]. (E1)

[...] Um pouco difícil, porque elas se apegam muito a você. (E3)

[...] Lidar com criança não é fácil, porque a gente fica emotiva, muito frágil. (E9)

$\mathrm{Na}$ perspectiva do cuidado integral e assistência de qualidade é esperado que o profissional estabeleça envolvimento com seu paciente, ao oferecer-lhe uma atenção humanizada. $^{24}$ Destaca-se que os dados foram coletados numa unidade de internação hospitalar, local onde geralmente se encontram pacientes cujo estágio da doença apresenta-se avançado, e os participantes lidam frequentemente com o processo de terminalidade.

[...] É difícil aceitar, terminalidade, essas coisas, [...] o adulto já viveu alguma coisa, a criança não [...] a gente acha que ainda tem muito para viver, por isso que é difícil de lidar com criança. (E8)

A criança portadora de doença em estágio avançado desestrutura a equipe de saúde, que sente dificuldades ao ter que lidar com este ser em processo de terminalidade, ainda no começo de sua vida. ${ }^{25}$ Em meio a isso, o profissional fragilizado experimenta sensações de frustração e impotência e isso pode ser explicado pelo fato destes profissionais serem formados com um conceito arraigado para cuidar trazendo a restauração da saúde e a cura, considerando a morte como fracasso. ${ }^{19}$

\section{CONSIDERAÇÕES FINAIS}

Este estudo evidenciou que no processo de enfrentamento emocional da equipe de enfermagem no cuidado a crianças com câncer hospitalizadas existe uma dualidade entre demonstração e repressão dos sentimentos. Estes profissionais transitam pela postura de flexibilidade, humanização e envolvimento, deixando aflorar seus sentimentos durante o cuidado. Por outro lado, tentam esconder suas emoções ao adotar uma aparente neutralidade emocional, apesar de se sentirem abalados e sofrerem com a situação das crianças com câncer.

Como implicações desta investigação destacam-se as reflexões dos profissionais envolvidos no cuidado de crianças com câncer e sobre o seu enfrentamento emocional nesse processo. Espera-se que este possa contribuir para o necessário investimento institucional na educação permanente e o desenvolvimento de estratégias que deem apoio psicológico, oferta de momentos de orientação e troca de experiências entre os profissionais. 


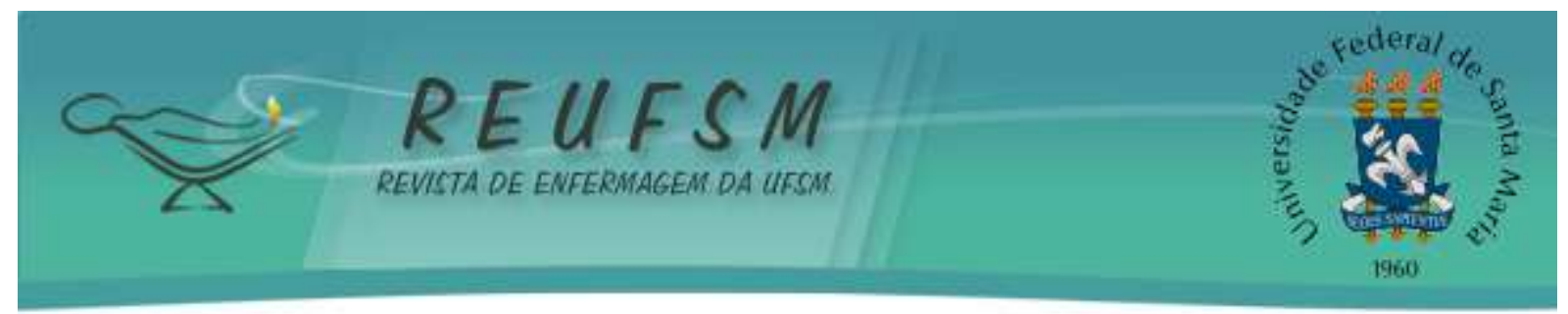

Destaca-se como uma limitação, o tempo escasso dos profissionais para responder às perguntas da entrevista. Assim, futuras pesquisas que contemplem estratégias metodológicas para abordagem do enfrentamento emocional dos profissionais poderão contribuir para o avanço do conhecimento da enfermagem.

Sugere-se ainda produção de conhecimento sobre as influências do apoio psicológico que aprofundem aspectos como a relação de empatia dos profissionais de enfermagem com as crianças e familiares, resistência dos mesmos em trabalhar neste setor e evidências sobre as estratégias gerenciais e de liderança em enfermagem para amenizar ou aliviar essas tensões.

\section{REFERÊNCIAS}

1. Siegel R, Ma J, Zou Z, Jemal, A. Cancer statistics. Ca Cancer J Clin [Internet]. 2014 [acesso em 2016 dez 03];64(1):9-29. Disponivel em: http://onlinelibrary.wiley.com/doi/10.3322/caac.21208/epdf.

2. Brasil. Ministério da Saúde. Instituto Nacional de Câncer (INCA). Tipos de Câncer Infantil [Internet]. 2016 [acesso em 2016 jan 31]. Disponível em: http://www2.inca.gov.br/wps/wcm/connect/tiposdecancer/site/home/infantil.

3. Santos PM, Silva LF, Depianti JRB, Cursino EG, Ribeiro CA. Os cuidados de enfermagem na percepção da criança hospitalizada. Rev Bras Enferm [Internet]. 2016 [acesso em 2016 nov 21];69(4):646-53. Disponível em: http://www.scielo.br/pdf/reben/v69n4/0034-7167-reben-6904-0646.pdf.

4. Weinstein AG, Henrich CC. Psychological interventions helping pediatric oncology patients cope with medical procedures: a nurse-centered approach. European J Oncology Nurs [Internet]. 2013 [acesso em 2018 mar 08];17(6):726-31. Disponível em: http://www.ejoncologynursing.com/article/S1462-3889(13)00048-3/fulltext.

5. Mukherjee S, Beresford B, Tennant A. Staff burnout in paediatric oncology: new tools to facilitate the development and evaluation of effective interventions. European J Cancer Care [Internet]. 2014 [acesso em 2018 mar 08];23(4):450-61. Disponível em: http://onlinelibrary.wiley.com/doi/10.1111/ecc.12176/pdf.

6. Nóia TC, Sant'Ana SER, Santos ADS, Oliveira SC, Veras SMCB, Lopes-Júnior LC. Coping with the diagnosis and hospitalization of a child with childhood cancer. Invest Educ Enferm [Internet]. 2015 [acesso em 2016 dez 03];33(3):466-71. Disponível em: http://aprendeenlinea.udea.edu.co/revistas/index.php/iee/article/view/24455/19990.

7. Salimena AMO, Teixeira SR, Amorim TV, Paiva ACPC, Melo MCSC. Estratégias de enfrentamento usadas por enfermeiros ao cuidar de pacientes oncológicos. Rev Enferm UFSM [Internet]. 2013 [acesso em 2018 abr 19];3(1):8-16. Disponível em: https://periodicos.ufsm.br/reufsm/article/view/6638.

8. Lima MJV, Cavalcante CM. As estratégias de enfrentamento/autocuidado utilizadas pelos trabalhadores de limpeza em um centro oncológico pediátrico. Rev SBPH [Internet]. 2015 


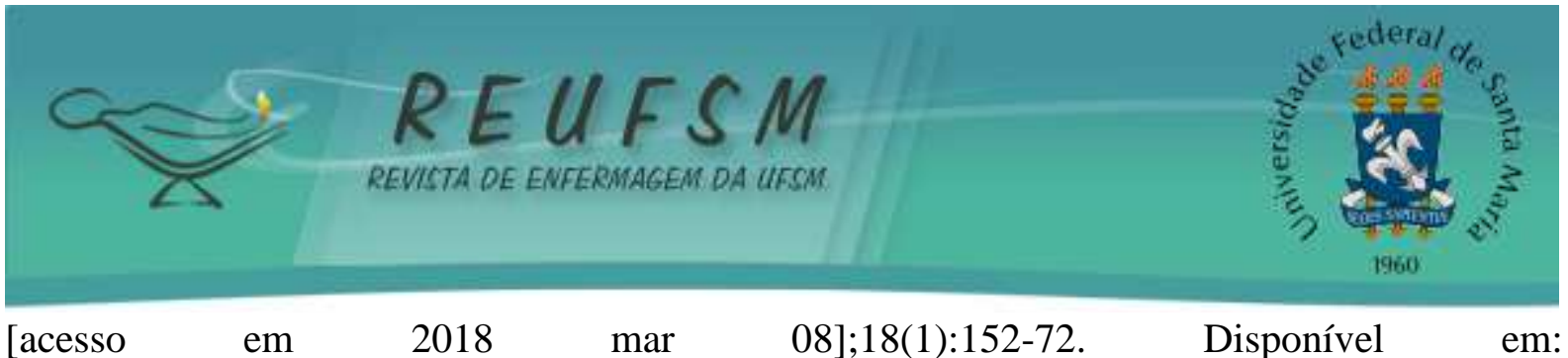
http://pepsic.bvsalud.org/pdf/rsbph/v18n1/v18n1a08.pdf.

9. Ferraza A, Muniz RM, Pinto KB, Viegas AC, Matos MR. Survival from Cancer in the family perspective. J Nurs UFPE [Internet]. 2016 [acesso em 2016 nov 18];10(3):1022-8. Disponível

em: http://www.revista.ufpe.br/revistaenfermagem/index.php/revista/article/view/7021/pdf_9844.

10. Silva TP, Leite JL, Santos NLP, Silva IR, Mendonça ACA, Santos MJC, et al. Cuidados de enfermagem à criança com câncer: uma revisão integrativa da literatura. Rev Enferm UFSM [Internet]. 2013 [acesso em 2016 jul 12];3(1):68-78. Disponível em: http://periodicos.ufsm.br/reufsm/article/view/6918/pdf.

11. Brasil. Ministério da Saúde. Conselho Nacional de Saúde. Resolução CNS nº 466, de dezembro de 2012. Dispõe sobre pesquisas e testes em seres humanos [Internet]. Diário Oficial da União: Brasília, DF; 2013 [acesso em 2016 jan 19]. Disponível em: http://conselho.saude.gov.br/resolucoes/2012/Reso466.pdf.

12. Minayo MCS. O desafio do conhecimento: pesquisa qualitativa em saúde. $12^{\mathrm{a}}$ ed. São Paulo: Hucitec; 2010.

13. Santos FC, Camelo SHH, Laus AM, Leal LA. O enfermeiro que atua em unidades hospitalares oncológicas: perfil e capacitação profissional. Enfermería Global [Internet]. 2015 [acesso em 2018 abr 19];(38):313-24 . Disponível em: http://scielo.isciii.es/pdf/eg/v14n38/pt_revision3.pdf.

14. Soares VA, Silva LF, Cursino EG, Goes FGB. O uso do brincar pela equipe de enfermagem no cuidado paliativo de crianças com câncer. Rev Gaúcha Enferm [Internet]. 2014 [acesso em 2016 jul 12];35(3):111-16. Disponível em: http://www.scielo.br/pdf/rgenf/v35n3/pt_1983-1447-rgenf-35-03-00111.pdf.

15. Garcia BL, Thofehrn MB, Porto AR, Moura PMM, Carvalho LA, Fernandes HN. Relação entre liderança e vínculos profissionais: percepção de enfermeiros. Rev Pesq Saúde [Internet]. 2017 [acesso em 2018 abr 20];18(2):114-8. Disponível em: http://www.periodicoseletronicos.ufma.br/index.php/revistahuufma/article/view/6715.

16. Lee EK, Ji EJ. The moderating role of leader-member exchange in the relationships between emotional labor and burnout in clinical nurses. Asian Nurs Res (Korean Soc Nurs Sci) [Internet]. 2018 [acesso 2018 mar 08];1-6. Disponível em: http://www.asiannursingresearch.com/article/S1976-1317(17)30437-1/pdf.

17. Góis ARS, Abrão FMS. O processo de cuidar do enfermeiro diante da morte. Rev Enferm UFSM [Internet]. 2015 [acesso 2016 jul 14];5(3):415-25. Disponível em: https://periodicos.ufsm.br/index.php/reufsm/article/view/15832/pdf.

18. Santos MA, Hormanez M. Atitude frente à morte em profissionais e estudantes de enfermagem: revisão da produção científica da última década. Ciênc Saúde Coletiva [Internet]. 2013 [acesso em 2017 maio 08];18(9):2757-68. Disponível em: http://www.scielo.br/pdf/csc/v18n9/v18n9a31.pdf.

19. Menegócio AM, Rodrigues L, Teixeira GL. Enfermagem oncologia: relação de afetividade ou meramente técnica? Ensaios Cienc, Cienc Biol Agrar Saúde [Internet]. 2015 


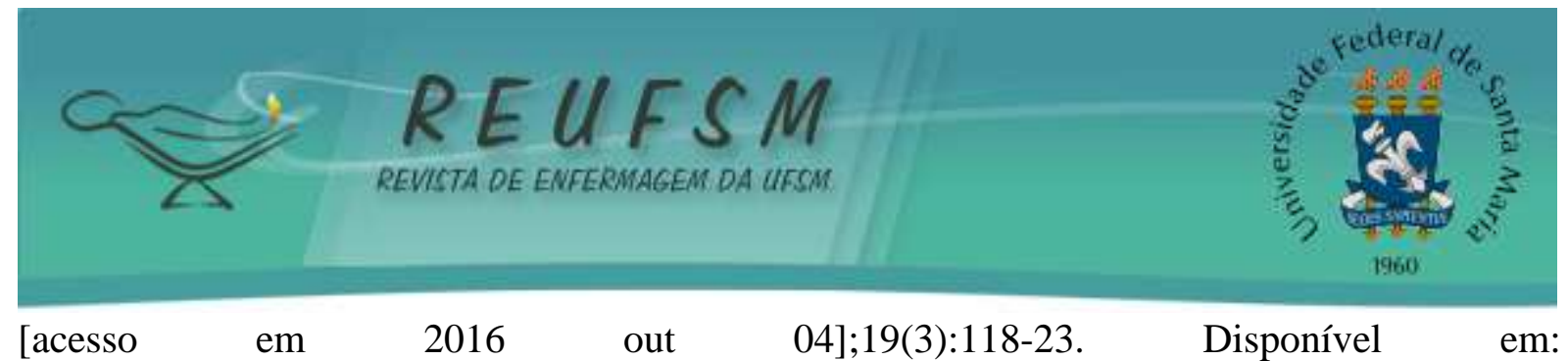
http://www.redalyc.org/pdf/260/26042169004.pdf.

20. Pye K. Exploring moral distress in pediatric oncology; a sample of registered practitioners. J Issues in Comprehensive Pediatric Nursing [Internet]. 2013 [acesso em 2018 mar 08];36(4):248-61. Disponível em: https://www.tandfonline.com/doi/abs/10.3109/01460862.2013.812693?journalCode=icpn20.

21. Silva MM, Vidal JM, Leite JL, Silva TP. Estratégias de cuidados adotadas por enfermeiros na atenção à criança hospitalizada com câncer avançado e no cuidado de si. Cienc Cuid Saude [Internet]. 2014 [acesso em 2018 abr 23];13(3):471-8. Disponível em: http://periodicos.uem.br/ojs/index.php/CiencCuidSaude/article/view/19937.

22. Pereira DMB, Bertoldi K, Roese A. Percepções dos profissionais de enfermagem na assistência a crianças portadoras de câncer. Rev Enferm UFSM [Internet]. 2015 [acesso em 2016 out 23];5(1):112-20. Disponível em: https://periodicos.ufsm.br/reufsm/article/view/13426/pdf.

23. Reis TLR, Paula CC, Potrich T, Padoin SMM, Bin A, Mutti CF, et al. Relações estabelecidas pelos profissionais de enfermagem no cuidado às crianças com doença oncológica avançada. Aquichan [Internet]. 2014 [acesso em 2018 abr 23];14(4):496-508. Disponível em: http://www.scielo.org.co/pdf/aqui/v14n4/v14n4a05.pdf.

24. Salimena AMO, Teixeira SR, Amorim TV, Paiva ACPC, Melo MCSC. O vivido dos enfermeiros no cuidado ao paciente oncológico. Cogitare Enferm [Internet]. 2013 [acesso em 2016 jul 23];18(1):142-7. Disponível em: http://revistas.ufpr.br/cogitare/article/view/31320/20027.

25. Turolla KR, Souza MC. Enfermagem Pediátrica oncológica: assistência na fase de terminalidade. Ensaios Cienc, Cienc Biol Agrar Saúde [Internet]. 2015 [acesso em 2017 mar 23];19(1):26-37. Disponível em: http://www.redalyc.org/pdf/260/26042167005.pdf.

Data de submissão: 24/05/2017

Data de aceite: $24 / 04 / 2018$

Autor correspondente: Nádia Fontoura Sanhudo

Email: nadiasanhudo@gmail.com

Endereço: Avenida Presidente Itamar Franco, $n^{\circ}$ : 1717, apartamento: 402. Bairro: São Mateus. Juiz de Fora. Minas Gerais, Brasil.

CEP: 36016-321 